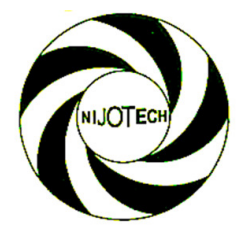

Nigerian Journal of Technology (NIJOTECH)

Vol. 35, No. 1, January 2016, pp. 85 - 90

Copyright@ Faculty of Engineering, University of Nigeria, Nsukka,

Print ISSN: 0331-8443, Electronic ISSN: 2467-8821

www.nijotech.com

http://dx.doi.org/10.4314/njt.v35i1.14

\title{
FINITE ELEMENT MODEL FOR PREDICTING RESIDUAL STRESSES IN SHIELDED MANUAL METAL ARC WELDING OF MILD STEEL PLATES
}

\author{
I. U. Musa1, ${ }^{1}$, M. O. Afolayan ${ }^{2}$ and I. M. Dagwa ${ }^{3}$ \\ 1,2Dept. of Mechanical Engineering, Ahmadu Bello University Zaria, Kanduna State NiGERIA. \\ 3DEPT. OF MECHANICAL ENGINEERING, UNIVERSITY OF ABUJA GWAGWALADA, ABUJA NIGERIA. \\ E-mail addresses: ${ }^{1}$ skimodadon@yahoo.com, ${ }^{2}$ tunde.afolayan@gmail.com, ${ }^{3}$ dagwaim@gmail.com
}

\begin{abstract}
This paper investigates the prediction of residual stresses developed in shielded manual metal arc welding of mild steel plates through Finite Element Model simulation and experiments. The existence of residual stresses that cause fatigue and distortion in welded structures has been responsible for failure of machine parts in service. These stresses if not properly controlled can lead to loss of lives and property. The highlight is that various trial and error welding runs have to be carried out while hoping for the best performance during operation. This is wasteful of time, material and finance. Thus the need to incorporate Finite Element Analysis prediction of residual stresses by computational methods to first determine satisfactory welding conditions before actual production. The geometry of the butt welded Low Carbon (ASTM A36) steel plates was modeled and the residual stresses simulated using ANSYS Multiphysics V14. Three experimental samples of similar geometry were also produced using the shielded manual metal arc welding process to verify the result. Low carbon steel (ASTM A36) was used as the parent metal, E066 electrodes were used to complete the weld. The generated residual stresses were measured using an X-Ray Diffractometer (XRD 6000). From the Finite Element Model Simulation, the transverse residual stress in the $X^{-}$ direction $\left(\sigma_{x}\right)$ had a maximum value of $375 \mathrm{MPa}$ (tensile) and minimum value of -183MPa (compressive) while in the $y$-direction $\left(\sigma_{y}\right)$, the maximum value of $172 \mathrm{MPa}$ (tensile) and minimum value of zero. The longitudinal stress in the $x$-direction $\left(\sigma_{x}\right)$ indicated a maximum value of $355 \mathrm{MPa}$ (tensile) and a minimum value of $-10 \mathrm{MPa}$ (compressive) while in the $y$-direction $\left(\sigma_{y}\right)$, the maximum value was $167 \mathrm{MPa}$ and the minimum value of the residual stress was 375MPa. The experimental values as measured by the $X$-Ray diffractometer were of reasonable correlation as transverse residual stress $\left(\sigma_{x}\right)$ along the weld line in the transverse $x$-direction varied from $353 \mathrm{MPa}$ (tensile) to $209 \mathrm{MPa}$ (compressive) while in the $y$-direction, stress $\left(\sigma_{y}\right)$ along the weld line varied from $177 \mathrm{MPa}$ (tensile) to zero. The longitudinal stress measured by the X-Ray diffractometer in the $x$-direction $\left(\sigma_{x}\right)$ varied from $339 M P a$ (tensile) to zero (compressive) while in the $y$-direction $\left(\sigma_{y}\right)$ varied from $171 \mathrm{MPa}$ (tensile) to $-366 \mathrm{MPa}$ (compressive). These results shows that the residual stresses obtained by prediction from the finite element method are in fair agreement with the experimental results. Based on this, it can be concluded that Finite Element Model can be used to replicate and determine the expected residual stresses that would be generated before an actual welding process is carried out.
\end{abstract}

Keywords: Residual stress, 3D FEM, Shielded manual metal arc welding, Low Carbon Steel (ASTM A36), X-Ray diffraction, degree of correlation

\section{INTRODUCTION}

Welding is defined by the American Welding Society (AWS) as a localized coalescence of Metals or nonmetals produced by either heating of the materials to a suitable temperature with or without the application of pressure, or by the application of pressure alone, with or without the use of filler metal [1]. Residual stress is defined as "the stress resident inside a component or structure after all applied forces have been removed" [2]. Compressive residual stress acts by pushing the material together, while tensile residual stress pulls the material apart. Residual stress affects are the following; distortion, Crack initiation and propagation. (Damage tolerance), Peen forming (controlled distortion), Fretting, Stress corrosion cracking (SCC) and hydrogen initiated cracking (HIC).

*Corresponding author, Tel: +234-803-563-5419 
Any of these effects if not checked is liable to cause failure during service. Thus the need to Finite element method to predict the expected residual stresses.

The finite element method (FEM) is a computational technique used to obtain approximate solutions of boundary value problems in engineering. The finite element method is a way of getting a numerical answer to a specific problem. A simple description of FEM is the cutting of a structure into several elements, describing the behaviour of each element in a simple way, reconnecting the elements at "nodes" as if it were pins or drops of glue that held the elements together [3].

Gurinder [4] carried out a research on finite element simulation of residual stress in butt welding of two AISI 304 stainless steel plates using a finite element based commercially available software, coupled thermal-mechanical three dimensional finite element model was developed by making an approximate geometry of the butt welded joint. Jeyakumar, et al [5] carried out a thermo-mechanical 3D finite element analysis to assess the residual stresses in the buttweld joints of ASTM A36 steel plates utilizing the commercial software package ANSYS. Stamenkovic [6] performed a 3D residual stress analysis of butt-weld joint of ASTM 36 steel plates $(100 \times 100 \times 3 \mathrm{~mm})$ with arc efficiency, $\eta=0.85$, arc voltage $(\mathrm{V})=24 \mathrm{~V}$, the current $(\mathrm{I})=180 \mathrm{~A}, \mathrm{r}_{\mathrm{b}}=3 \mathrm{~mm}$ and welding speed $=5$ $\mathrm{mm} / \mathrm{sec}$. The peak temperature reached $1973 \mathrm{~K}$ with tensile stresses were developed in the weld zone.

\section{METHODOLOGY}

The material properties are shown in Table 2. These properties vary with temperature during mechanical operations like welding, smelting, forging etc. These were taken into consideration in this work.

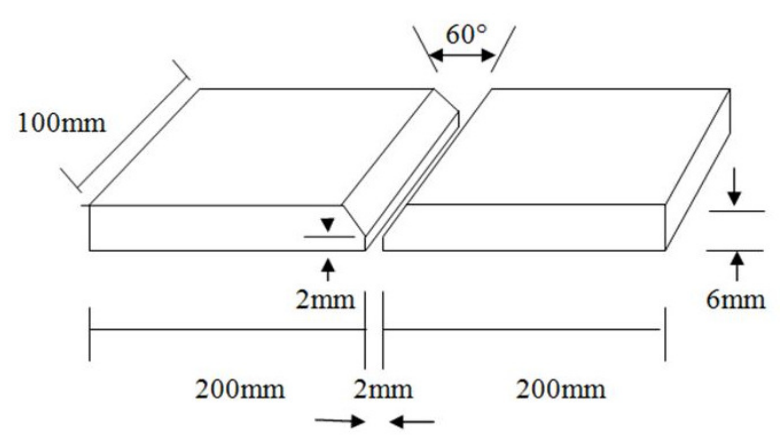

Figure 1: Butt Welded Low Carbon Steel (ASTM A36) plates

\subsection{Finite Element Analysis}

In this study, the butt-weld joint of two mild steel plates $(200 \times 100 \times 6 \mathrm{~mm})$ was modeled using ANSYS Multi-physics V14 as shown in Figure 1. To simplify the welding simulation, the thermal and mechanical analysis was performed separately.

Thermal analysis has been carried out using the 3D element SOLID 70, an eight node quadrilateral element with a single degree of freedom having temperature at each node. While the Structural analysis has been carried out using the 3D element SOLID 185, an eight node quadrilateral element having three degrees of freedom at each node (translation in the nodal $\mathrm{x}, \mathrm{y}$ and $\mathrm{z}$ directions). The mesh generated had 14073 nodes and 2380 elements, this is shown in Figure 2. The analysis was solved and the residual stresses generated were documented.The elemental composition of Low Carbon Steel (ASTM A36) is shown in Table 1.

Table 1: Elemental Composition of ASTM A36 Low Carbon Steel

\begin{tabular}{cc}
\multicolumn{3}{c}{ Carbon Steel } \\
\hline Element & Content \% \\
\hline $\mathrm{C}$ & $0.25-0.290$ \\
$\mathrm{Cu}$ & 0.20 \\
$\mathrm{Fe}$ & 98.0 \\
$\mathrm{Mn}$ & 1.03 \\
$\mathrm{P}$ & 0.040 \\
$\mathrm{Si}$ & 0.280 \\
\hline
\end{tabular}

Source [8]

\subsection{Specimen Preparation}

The experiment was carried out on a welding jig and both plates were clamped at the ends to ensure rigidity during the welding process. The plates were setup for the weld according to the geometry described in Figure 1.

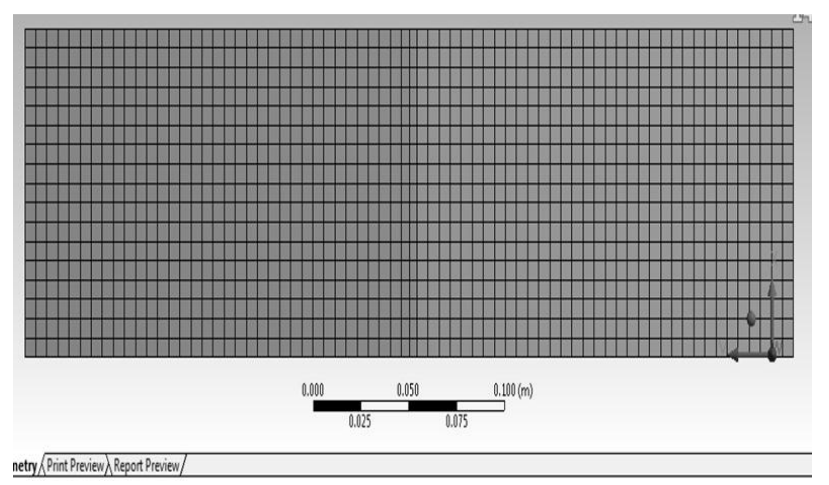

Figure 2: Meshed model of Low Carbon Steel (ASTM A36) plates [7] 
Table 2: Material properties of Low Carbon Steel (ASTM A36)

\begin{tabular}{|c|c|c|c|c|c|c|}
\hline No & Temperature (K) & $\begin{array}{l}\text { Specific heat } \\
(\mathrm{J} / \mathrm{kg} . \mathrm{K})\end{array}$ & $\begin{array}{l}\text { Conductivity } \\
(\mathrm{W} / \mathrm{m} . \mathrm{K})\end{array}$ & $\begin{array}{l}\text { Yield stress } \\
\quad(\mathrm{MPa})\end{array}$ & $\begin{array}{c}\text { Thermal } \\
\text { Expansion } \\
\text { Coeff. }\left(10^{-5} / \mathrm{K}\right)\end{array}$ & $\begin{array}{c}\text { Young's } \\
\text { Modulus } \\
(\mathrm{GPa})\end{array}$ \\
\hline 1 & 273 & 480 & 60 & 380 & 1.1 & 210 \\
\hline 2 & 373 & 500 & 50 & 340 & 1.15 & 200 \\
\hline 3 & 473 & 520 & 45 & 315 & 1.2 & 200 \\
\hline 4 & 673 & 650 & 38 & 230 & 1.3 & 170 \\
\hline 5 & 873 & 750 & 30 & 110 & 1.42 & 80 \\
\hline 6 & 1073 & 1000 & 25 & 30 & 1.45 & 35 \\
\hline 7 & 1273 & 1200 & 26 & 25 & 1.45 & 20 \\
\hline 8 & 1473 & 1400 & 28 & 20 & 1.45 & 15 \\
\hline 9 & 1673 & 1600 & 37 & 18 & 1.45 & 10 \\
\hline 10 & 1823 & 1700 & 37 & 15 & 1.45 & 10 \\
\hline
\end{tabular}

Using the shielded manual metal arc equipment and E6011 electrodes, the welding was carried out in a single pass which lasted for 50 seconds. The specimen were then allowed to cool down to room temperature. All welding precautions were taken into consideration during the specimen production to ensure the reduction of error. Theoretically, the amount of heat input, $Q$ is governed by the equation (1) [10].

$$
Q=\frac{\eta V I}{v x}
$$

The heat input during the welding process is given in equation (1)

In (1), $\eta$ is the arc efficiency , $\mathrm{V}$ is the arc voltage (V), I is the current (I), $v$ is the travel speed $(\mathrm{mm} / \mathrm{s}), \mathrm{x}$ is the electrode diameter $(\mathrm{mm})$. The weld parameters were: $\eta=0.75, \mathrm{~V}=25 \mathrm{~V}, \mathrm{I}=90 \mathrm{~A}, v=2(\mathrm{~mm} / \mathrm{s}), \mathrm{x}=$ $3.142 \mathrm{~mm}$.

$$
Q=\frac{0.75 \times 25 \times 90}{0.002 \times 0.003142}=268,539,147 \times\left(\frac{W}{m^{2}}\right)
$$

After the welding process, the samples were cleaned with a wire brush to remove carbon deposits and washed in a solution of nitric acid (10\% nitric acid and $90 \%$ water). Three experimental samples were produced as shown in Figure 3.

\subsection{X-ray Diffraction Measurement of Residual Stresses}

For measurements of residual stress, the developed strain is determined using a portable X-ray Diffractometer. This strain is then converted to the expected residual stress which is governed by Braggs law [12].

$$
n \lambda=2 d \sin \theta
$$

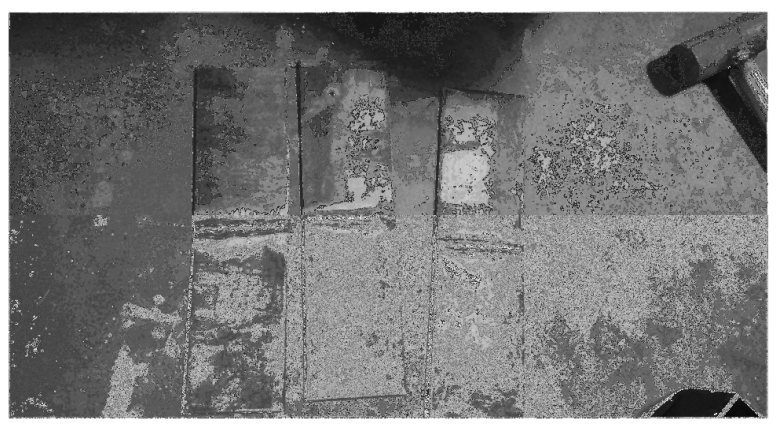

Figure 3: Low Carbon Steel Plates welded specimens [11]

Here $\lambda$ is the wavelength; $d$ is the inter-planar spacing, $\theta$ is the angle between the Incident ray and the scattering planes and $n$ is the order of reflection For the highest peak variation $(\Delta \theta)$ in the crystal lattice, the highest possible angle $(\theta)$ was chosen to determine the diffraction peak. A monochromatic beam with a wavelength of $\lambda=1.5418740 \AA(\mathrm{Cu}-\mathrm{K}) \alpha$ was used during X-ray diffraction patterns [12]. The operating voltage was $40 \mathrm{kV}$ and current of $30 \mathrm{~mA}$. The method used was the two angle technique, with measurement of $\psi=0^{\circ}, 10^{\circ}, 20^{\circ}, 30^{\circ}, 40^{\circ}, 50^{\circ}$ and $60^{\circ}$.The specimen to be measured was mounted on joint X-ray/detector tube and rotated according to the specified $\psi$ angles in the direction of the residual stress to be measured. XMAS software was used for generating the X-ray diffraction patterns, followed by computation of the longitudinal and transversal of the residual stresses. The specimen as mounted on the Xray diffractometer target is shown in Figure 4. 


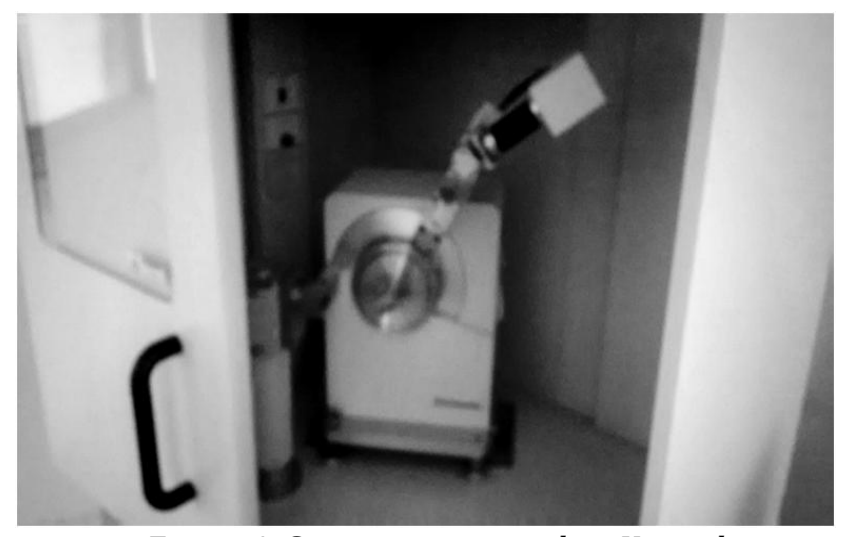

Figure 4: Specimen mounted on X-ray detector tube [8]

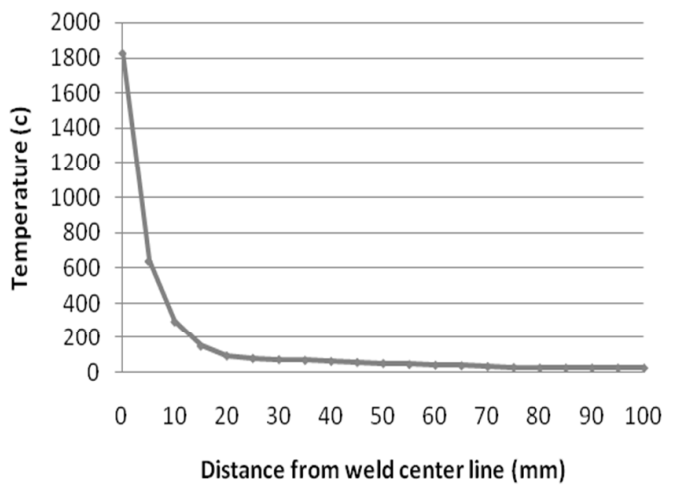

Figure 6: Temperature variation with distance along the transverse direction

\section{RESULTS}

The of the Finite element analysis showing the contour plot for temperature distribution on the plate at 25 seconds, the temperature variation with the with distance along the transverse direction and the contour plot of the residual stresses are shown in Figures 5, 6 and 7 respectively.

\subsection{Comparison of Residual Stresses from X-Ray diffraction and Finite Element Model Simulation}

A graphical comparison of the Transverse Residual stresses obtained from the X-ray diffraction and Finite Element Model Simulation in the $\left(\sigma_{\mathrm{x}}\right)$ and $\left(\sigma_{\mathrm{y}}\right)$ direction along the weld line are presented in figures 8 and 9 respectively. While the graphical comparison of the Longitudinal Residual stresses obtained from the X-ray diffraction and Finite Element Model Simulation in the $\left(\sigma_{x}\right)$ and $\left(\sigma_{y}\right)$ direction along the weld line are presented in figures 10 and 11 respectively

\section{DISCUSSIONS}

Figure 5 shows the temperature distribution on the plate and the maximum temperature can be seen from

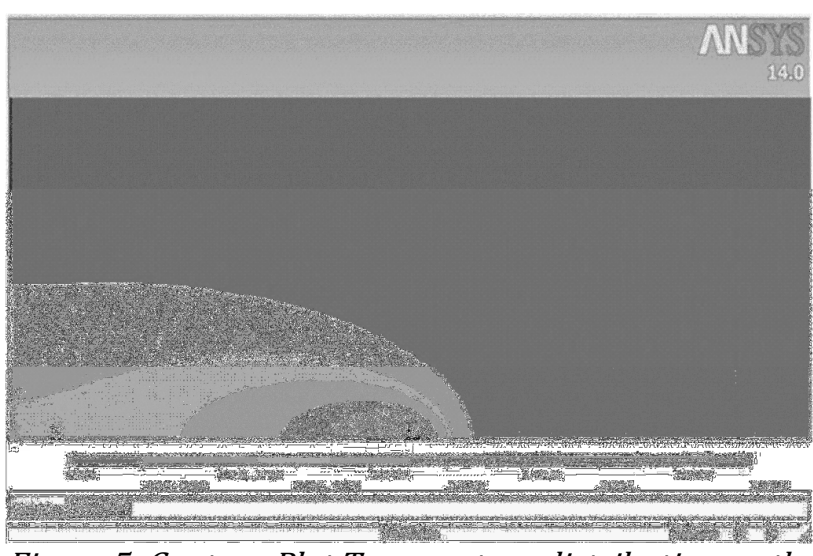

Figure 5: Contour Plot Temperature distribution on the plate at 25 seconds

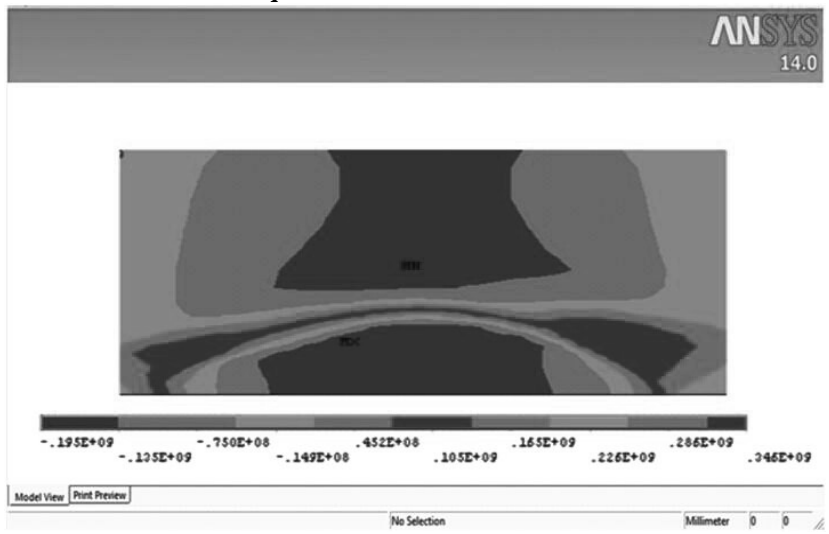

Figure7: Contour plot of residual Stresses $\left(\mathrm{N} / \mathrm{m}^{2}\right)$

the contour plot. Heat flux generated was $268,539,147$ $\left(\mathrm{W} / \mathrm{m}^{2}\right)$. The initial temperature was $27^{\circ} \mathrm{C}$ and convection coefficient of $15 \mathrm{~W} / \mathrm{m}^{2} \mathrm{C}$. The maximum temperature shown was at $1827^{\circ} \mathrm{C}$ at the node as the heat flux moved along the weld line. Which in real case was the arc produced by the electrodes.

Figure 6 shows the temperature variation with distance along the transverse direction on the steel plates away from the heat affected zone (HAZ). It can be seen that the temperature is maximum around the line of the welding and gradually reduces towards the edge of the plate. The maximum temperature was $1827^{\circ} \mathrm{C}$ while that at the end of the plate was maintained at around $27^{\circ} \mathrm{C}$.

The stress intensity plot shown in Figure 7 indicates the accumulation of stresses around the filler metal which is the HAZ region. Based on the intensity plot, the transverse stress in the $\mathrm{x}$-direction $\left(\sigma_{\mathrm{x}}\right)$ had a maximum value of $375 \mathrm{MPa}$ (tensile) and minimum value of $-183 \mathrm{MPa}$ (compressive) while in the $\mathrm{y}$ direction $\left(\sigma_{\mathrm{y}}\right)$, the maximum value of $172 \mathrm{MPa}$ (tensile) and minimum value of zero. 


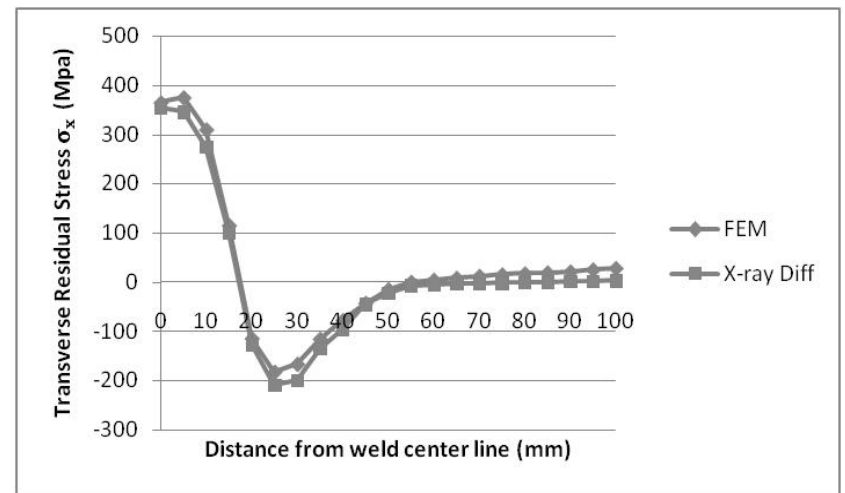

Figure 8: Comparison of the $x$-ray diffraction and FEM simulation of the transverse residual stress $\left(\sigma_{x}\right)$ along the weld line.

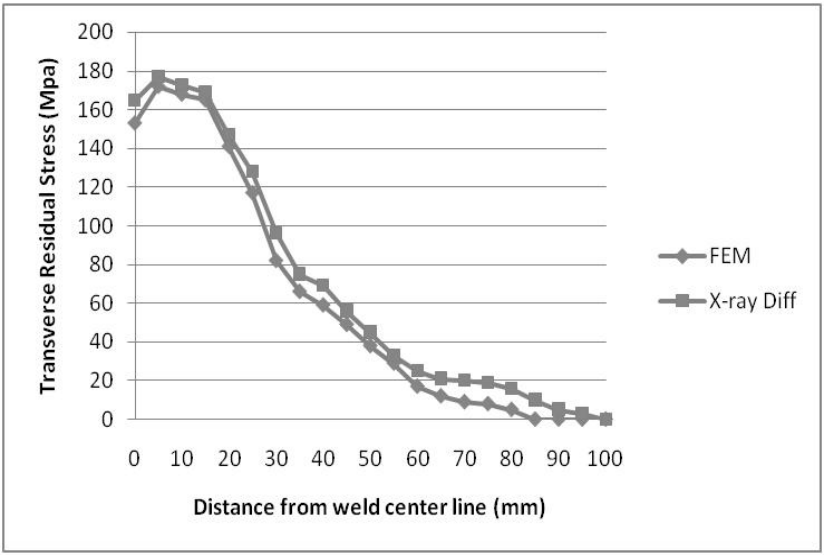

Figure 9: Comparison of the experimental and FEM transverse residual stress $\left(\sigma_{y}\right)$ along the weld line

The longitudinal stress in the $\mathrm{x}$ direction $\left(\sigma_{\mathrm{x}}\right)$ indicated a maximum value of $355 \mathrm{MPa}$ (tensile) and a minimum value of $-10 \mathrm{MPa}$ (compressive) while in the $\mathrm{y}$ - direction $\left(\sigma_{\mathrm{y}}\right)$, the maximum value was $167 \mathrm{MPa}$ and the minimum value of the residual stress was $375 \mathrm{MPa}$. This is in agreement with the result elsewhere [5]. With reference to Figure8the line graph comparison of the X-Ray Diffraction and FEM simulation of the transverse residual stress $\left(\sigma_{\mathrm{x}}\right)$ along the weld line in the transverse direction is shown. The experimental XRD values of residual stress varied from 353Mpa (tensile) to-209MPa (compressive) while the FEM transverse residual stress varied from $365 \mathrm{MPa}$ (tensile) to -183MPa (compressive).

Figure 9 shows the comparison of the experimental and FEM transverse residual stress $\left(\sigma_{\mathrm{y}}\right)$ along the weld line in the transverse direction. The experimental value varied from $177 \mathrm{MPa}$ (tensile) to zero while the FEM value varied from $172 \mathrm{MPa}$ (tensile) to zero.

Figure 8 and 9 show that tensile stresses were developed in the weld zone. These tensile stresses

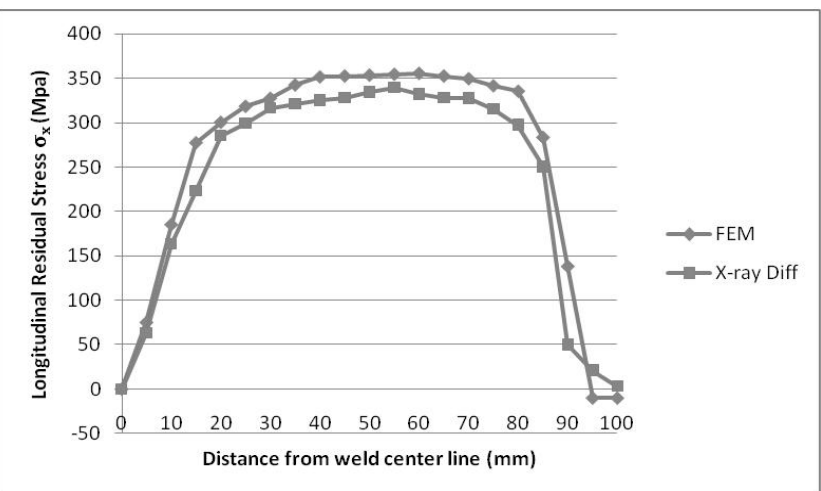

Figure10: Comparison of the $x$-ray diffraction and FEM simulation of the longitudinal residual stress $\left(\sigma_{x}\right)$ along the weld line in the longitudinal direction

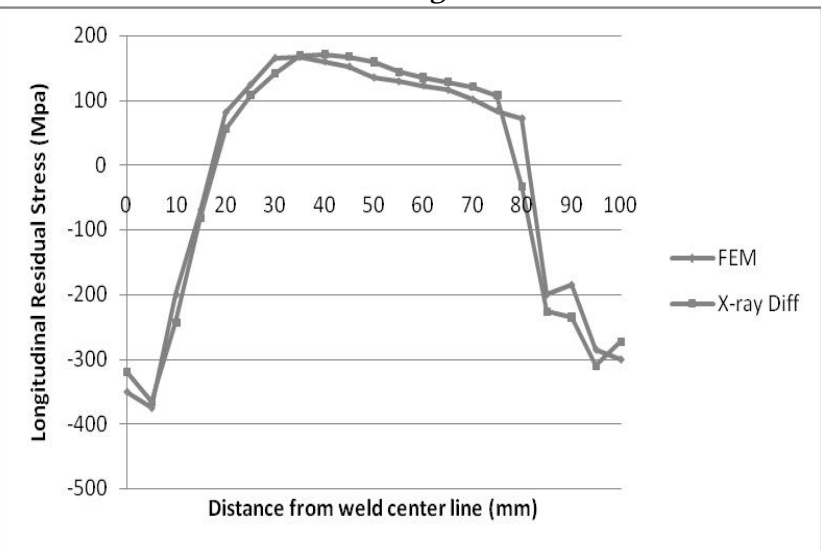

Figure11: Comparison of the experimental and FEM longitudinal residual stress $\left(\sigma_{y}\right)$ along the weld line

gradually decreased in the transverse direction away from the weld center line and become compressive towards the edge of the plate. The peak tensile residual stress estimates from the X-ray diffraction measurement is in agreement with those obtained from the Finite Element Simulation Result. This is equally similar to the result obtained [5].

Figure10 shows the comparison of the $\mathrm{x}$-ray diffraction and FEM simulation of the longitudinal residual stress $\left(\sigma_{x}\right)$ along the weld line in the longitudinal direction. The experimental values of residual stress varied from 339MPa (tensile) to zero (compressive) while the FEM longitudinal residual stress varied from $355 \mathrm{MPa}$ (tensile) to $-10 \mathrm{MPa}$ (compressive).

Figure11 shows the comparison of the experimental and FEM longitudinal residual stress $\left(\sigma_{\mathrm{y}}\right)$ along the weld line in the longitudinal direction. The experimental value of Residual stress varied from $171 \mathrm{MPa}$ (tensile) to $-366 \mathrm{MPa}$ (compressive) while the FEM value varied from $167 \mathrm{MPa}$ (tensile) to $-375 \mathrm{MPa}$ (compressive). 
Figure10 and11 show that tensile stresses were developed in the weld zone. These tensile stresses gradually decrease in the longitudinal direction away from the weld centre line and become compressive towards the edge of the plate. The peak tensile residual stress estimates from the X-ray diffraction measurement is also in good agreement with those obtained from the Finite Element Simulation Result. This is also similar to the result obtained [6].

\section{CONCLUSIONS}

Experimental samples of ASTM A36 steel plates (200 x $100 \times 6$ ) were successfully butt welded and the residual stresses generated were measured using an X-Ray Diffractometer. Also, a Finite Element Analysis simulation was carried out using commercial software package ANSYS Multi-physics V14 to model and estimate the residual stresses in the butt welded ASTM A36 steel plates. A three-dimensional finite element welding simulation was carried out on a onepass Manual Metal Arc Welding plain joint structure. The welding simulation was considered as a sequential un-coupled thermo-mechanical analysis and the element birth and death technique was employed for the simulation of filler metal deposition [13]. The comparison of the residual stresses (transverse and longitudinal) determined by the finite element method and X-Ray diffraction experiment are shown in Figure 8-11 respectively. These show that the results obtained by the finite element method are in fair agreement with the experimental results. Based on this, it can be concluded that Finite Element Model can be used to replicate and determine the expected residual stresses that would be generated before the actual weld is carried out.

\section{REFERENCES}

[1] Mackerle, J. "Finite element analysis and simulation of welding-an addendum: a bibliography (19962001), Modelling Simul. Mater. Sci. Eng., 10:295-318, 2004.
[2] Barosum, Z. and Barosum, I. "Residual stress effects on fatigue life of welded structures using LEFM", Engineering Failure Analysis, vol. 1, no 16, 2009, pp. 449-467.

[3] David, R. "Finite Element Analysis," M.sc Thesis, Massachusetts Institute of Technology, Cambridge, MA 02139, 2001.

[4] Gurinder, S. "Finite element simulation of residual stress in butt welding of two AISI 304 stainless steel plates", International Journal on Theoretical and Applied Research in Mechanical Engineering, Volume - 2, Issue - 1, 2013, p75.

[5] Jeyakumar, M., T. Christopher, T., Narayanan, R. and Nageswara B. (2013)"Residual Stress Evaluation in Butt-welded joint of ASTM A36 Steel Plates", International Journal of Electronics Communication and Computer Engineering, Vol. 4, 2013, p.581-587.

[6] Stamenkovic, D. and Ivana, V "Finite Element Analysis of Residual Stress in Butt Welding Two Similar Plates", Scientific Technical Review, Vol. 511, No. 1, 2009, pp. 57-60

[7] ANSYS Multiphysics V14.

[8] National Steel Raw Materials Exploration Agency, Kaduna.

[9] Harshal, K. "Finite element model to predict residual stresses in MIG welding", International journal of mechanical engineering and technology (IJMET) Volume 3, Issue 3, September - December, 2012, pp. 350-361.

[10] Naeem, D. "Analysis of weld-induced residual stresses and distortions in thin-walled cylinders", Journal of Mechanical Science and Technology (23), 2009, pp.1118-1131.

[11] Gorgeous metal makers limited, Nigeria.

[12] Cook, E., Johnson, D.,Matti, J., and I. Zemmels, I. "Methods of sample preparation and $\mathrm{x}$-ray diffraction data analysis", Institute of Geophysics and Planetary Physics, University of California, Riverside, Contribution No 74, 2006, p5.

[13] Fanous, Z., Wifi, S. And Younan, A."3-D Finite Element Modeling of the Welding Process Using Element Birth and Element Movement Techniques", Journal of Pressure Vessel Technology, 125, 2003, pp. 144-150. 